\title{
Brasileiros nas Bienais de Paris (anos 1960)
}

\author{
Maria de Fátima Morethy Couto* \\ Universidade Estadual de Campinas
}

\begin{abstract}
Resumo
0 artigo analisa a participação de jovens artistas brasileiros nas Bienais de Paris realizadas na década de 1960 e discute a importância do evento no cenário artístico francês do período. Sem romper com o modelo de Veneza, a Bienal de Paris trazia como novidade a aposta em novos valores. Para jovens artistas de países periféricos um evento desse porte significava a possibilidade de mostrar seu trabalho a um público maior, e talvez mais qualificado. O Brasil se destaca em relação aos países da América do Sul por enviar representações significativas e conquistar diversos prêmios.
\end{abstract}

\section{Palavras-chave}

Bienais de arte, Bienal de Jovens de Paris, arte brasileira moderna e contemporânea.

\begin{abstract}
The article analyzes the participation of young Brazilian artists in the Paris Biennials held in the 1960s and discusses the importance of the event in the French art scene of the period. Without breaking with the model of Venice, the Paris Biennale brought as novelty the betting on new values. For young artists from peripheral countries an event of this size could mean a unique chance to show their work to a larger and perhaps more qualified audience. Brazil stands out in relation to other South American countries sending significant delegations to the Paris Biennials and winning several awards.
\end{abstract}

\section{Key-words}

Biennials, Biennale de Jeunes de Paris, Brazilian modern and contemporary art.

\footnotetext{
* Professora Livre-Docente do Instituto de Artes da Unicamp. Autora do livro Por uma vanguarda nacional. A crítica brasileira em busca de uma identidade artística - 1940/1960 (Ed. Unicamp, 2004) e co-autora/organizadora dos livros ABCdaire Cézanne (Flammarion, 1995), Instituições da Arte (Zouk, 2012) e Espaços da arte contemporânea (Alameda, 2013). 


\section{As Bienais de Paris}

Em carta endereçada ao critico inglês Guy Brett, datada de 12 de abril de 1967, Hélio Oiticica alude à sua futura participação na Bienal de Paris daquele ano e comenta que seu plano inicial havia sido o de conceber um trabalho coletivo, juntamente com Lygia Clark, Rubens Gerchman, Antonio Dias e seu irmão Cesar Oiticica. Dias, cabe lembrar, ganhara um prêmio na edição anterior dessa Bienal e morava em Paris desde então. Todavia, a idade de Clark era superior à permitida pelos regulamentos do evento francês (35 anos) e o espaço designado para a participação do Brasil era muito reduzido. Oiticica informa Brett de sua intenção de enviar seis relevos espaciais para Paris, que ele realizaria para a ocasião, e justifica que embora os relevos sejam antigos enquanto proposta (do início dos anos 1960), ele os considera importantes em sua trajetória e não gostaria que permanecessem como projetos. ${ }^{1}$

Oiticica e Guy Brett corresponderam-se com frequência entre os anos de 1967 e 1968 em função da preparação de uma exposição individual do artista brasileiro em Londres, exposição essa que vinha sendo constantemente adiada e apenas ocorreria no início de $1969 .{ }^{2}$ As longas cartas de Oiticica a Brett tratam essencialmente desse tema, mas também abordam outros assuntos, como o que nos interessa aqui. Em 27 de outubro, Oiticica menciona novamente sua participação na Bienal de Paris, agora de modo mais concreto, uma vez que a mostra tivera início em 30 de setembro. Ao invés dos relevos espaciais, Oiticica terminara por enviar alguns de seus parangolés, mas ficara desapontado com o modo como eles foram "exibidos":

Também enviei cerca de cinco capas [parangolés] para a Bienal de Paris, capas-poema e de protesto, mas, apesar de eu ter sido informado que elas chamaram a atenção, elas não foram bem apresentadas: não havia nenhuma informação sobre sua natureza e todas continham palavras que ninguém leu, claro. Mas as melhores capas estão lá, especialmente uma preta, como uma rede que se veste, e com um bolso do qual você pode retirar uma faixa de nylon com um saco de palha na extremidade e com palavras escritas sobre a faixa (Estou possuído). Gosto especialmente dessa. Você já esteve por lá? A Embaixada do Brasil em Londres vai expor esses trabalhos, junto com os outros artistas que foram escolhidos para Bienal de Paris (os brasileiros). ${ }^{3}$

\footnotetext{
1 Carta de HélioOiticica para Guy Brett, datada de 12 de abril de 1967. Arquivos da Whitechapel Gallery, Londres. Trecho original: "The main reason for executing them now is that I still find them important in my development and that I don't want them to remain as projetcts".

2 Trata-se da exposição The WhitechapelExperiment, que foi realizada na galeria Whitechapel em Londres, de fevereiro a abril de 1969. O convite para a exposição surgira da equipe da galeria Signals, ativa em Londres de 1964 a 1966. Guy Brett era um dos colaboradores da Signals e empenhou-se ao máximo para que a mostra de Oiticica viesse a acontecer.

${ }^{3}$ No original: "I sent also some Five capes to Paris Biennal, poem and protest ones, but, although I have been told they interested people, they were not well introduced: there was no information about their nature and all of them contained words that no one read, of course. But the best capes are there, specially a Black one, as lace you can put on, from which pocket you can pull out a nylon ribbon with a sack of straw in the extremity and with written words on the ribbon (I'm possessed). I like that one specially. Have you been there? The Brazilian Embassy is going to exhibit them at London with the other artists that were chosen for Paris Biennial (Brazilian ones)". Carta de Hélio Oiticica para Guy Brett, datada de 27 de outubro de 1967. Arquivos da WhitechapelGallery, Londres.
} 
Nesse ano de 1967 a delegação brasileira ficara a cargo do crítico Antonio Bento, que, segundo seu texto de apresentação, selecionara jovens artistas que apostavam no futuro, "criadores de novas formas, objetos, estilos e tendências, que procuram atingir um público vasto e não somente uma elite, como era o hábito do passado e talvez ainda de nossos dias" (Bienal de Jovens de Paris, 1967: 39-41). Certamente não por acaso, tendo em vista a situação política cada vez mais tensa do Brasil, mas também em concordância com seu pensamento anterior, Bento acentua a necessidade de liberdade de criação em "um século voltado à democracia e à difusão das artes em todas as camadas da sociedade" e afirma que a seleção brasileira se deu "a partir de uma visão histórica que é a da liberdade de criação artística em escala mundial".

Ferrenho defensor da abstração informal nos anos 1950, Bento levou a Paris obras diversificadas, de artistas de interesses distintos, e o conjunto impressiona por sua atualidade, se 0 analisarmos à luz do debate em curso no Brasil do período. Além de Oiticica e de Maria Bonomi, nomes de maior circulação e reconhecimento no cenário nacional, ${ }^{4}$ integravam a delegação brasileira artistas que participavam das exposições de vanguarda do período (Opinião 65, Opinião 66 e Nova Objetividade Brasileira), como Rubens Gerchman, Chico Liberato, Gastão Manoel Henrique e Avatar Moraes, ou que haviam passado pelos ateliês do Museu de Arte Moderna do Rio de Janeiro (caso de José Lima) e/ou começavam a se envolver com questões ligadas à Nova Figuração, como Regina Vater e Anna Bella Geiger, com suas gravuras viscerais. Cabe lembrar que a Bienal de Paris, a partir de 1963, passou a acolher e premiar obras no campo da arquitetura, filme de arte, trabalhos de equipe e composição musical. ${ }^{5}$ Assim, a delegação brasileira também levou a Paris trabalhos de dois arquitetos (Paulo Casé e André Lopes), um compositor (Reginaldo Carvalho) e um cineasta (Antonio Carlos Fontoura). Ressalto que o filme de Fontoura, Ver e ouvir, integrara a mostra Nova Objetividade Brasileira e versava sobre a trajetória de três jovens artistas (Dias, Gerchman e Roberto Magalhães), com a contribuição de Ferreira Gullar. ${ }^{6}$ Ao total, 55 obras - entre pinturas, esculturas, desenhos e

\footnotetext{
${ }^{4}$ Em 1964, Bonomi participara da representação brasileira na Bienal de Veneza, por exemplo.

${ }^{5}$ Desde sua primeira edição a Bienal de Paris tinha uma seção dedicada à decoração teatral.

${ }^{6}$ Com aponta Antonio Bento em seu texto, dois dos artistas discutidos por Fontoura em seu filme ganharam prêmios na IV Bienal de Paris (Dias e Magalhães) e o terceiro (Gerchman) participava daquela edição da Bienal. Segundo descrição de Paulo Reis, 0 filme de Fontoura "era formado por quatro segmentos: "Roberto Magalhães: um jogo de espelhos" (numcenário de parque de diversões, depoimentos do artista sobre sua trajetória desde sua infância), "Antonio Dias: preparação para o contra-ataque" (a casa e ateliê do artista, visita a uma exposição), "Rubens Gerchman: os desconhecidos" (suas pinturas colocadas na rua e perguntas aos passantes sobre alguns de seus significados) e "Ferreira Gullar: a pintura fala" (uma espécie de amarração conceitual dos artistas e um clima da arte daquele momento). 0 filme de Fontoura foi uma resposta sensivelàsmanifestaç̃oes radicais dos três artistas na cidade do Rio de Janeiro, Antonio Dias, Rubens Gerchman e Roberto Magalhães. Suas imagens "costuravam" aquelas trêspoéticas na tessitura da cidade e na discussão de seu tempo (linguagem da arte e sociedade). 0 último segmento, com texto/poesia narrado e de autoria de Ferreira Gullar, assemelhava-se a uma outra declaração de vanguarda, mais cifrada, ao detectar no seio da cidade contemporânea (1966), entre seus novos circuitos e caos, a presença de uma arte (pintura) que ainda preservava a vontade de comunicação e apontava um rompimento de linguagens". (Reis, 2005: 151-152).
} 
gravuras - foram expostas nessa ocasião, além de dois projetos de arquitetura, o filme citado, e quatro composições musicais.

A Bienal de Jovens foi criada em 1959, com o claro intuito de reconduzir Paris à condição de centro internacional de referência no campo artístico, apostando na produção contemporânea, que não encontrava ainda forte apoio institucional na França. ${ }^{7}$ Nas palavras de seu organizador, Raymond Cogniat:

Os grandes confrontos internacionais se multiplicam. Veneza e São Paulo servem de exemplo e proliferam. A França, que ocupa um lugar de destaque nas artes, não poderia ficar de fora de um movimento dessa natureza, que permite ampla informação e expande os intercâmbios intelectuais. Rejeitando todo espírito de rivalidade, nosso programa se insere no vasto inventário da cultura atual. Ao lado das prestigiosas exposições de Veneza e São Paulo, que prestam homenagem aos artistas que puderam afirmar sua personalidade e cuja influência marca a arte de seu tempo, optamos por fazer da Bienal de Paris um local de encontro e de experiência para os jovens, um lugar aberto às incertezas e esperanças. (...) Reservada para artistas com menos de 35 anos, esta manifestação não pode, como as outras exposições, brilhar pelo esplendor de suas estrelas. Ela quer ser um instrumento de trabalho colocado a serviço daqueles que buscam e se buscam. ${ }^{8}$

Tratava-se portanto de um projeto político que foi implementado após a malograda participação da França na Bienal de Veneza de 1958, quando 0 país não conquistou nenhum dos prêmios principais. $^{9}$ Segundo KrystelLavaur, autora de dois estudos acadêmicos sobre as Bienais de Paris, a ideia de criar uma nova bienal com um enfoque diferenciado - um "panorama da jovem criação internacional" - partiu de Cogniat, comissário francês da Bienal de Veneza de 1958, que a levou ao recém-nomeado Ministro da Cultura, André Malraux:

Esta ação recebeu a aprovação do ministro, que dirigia sua política para uma revalorização da cena artística parisiense e desejava criar na capital uma dinâmica que pudesse seduzir o mercado. (...) Ao longo dos anos 1950/60, as únicas manifestações francesas capazes de apresentar um panorama das artes eram os Salões, que se ancoravam em uma tradição acadêmica. (...) A Bienal se mostra então (1959) como um contraponto ao academismo,

\footnotetext{
${ }^{7}$ Esta situação se modificaria no decorrer dos anos 1970/80, com a criação do Centre Georges Pompidou e do Museu Nacional de Arte Moderna, da FIAC (Feira Internacional de Arte Contemporânea), dos Fundos Regionais de Arte contemporânea, dos Centros de Arte Contemporânea, entre outros. Essa reorientação do campo artístico na França dos anos 1980, com estruturas oficiais mais permeáveis ao trabalho de jovens artistas, acabaria por afetar diretamente a Bienal de Jovens de Paris, que entraria em crise, apesar do apoio de Jack Lang, Ministro da Cultura no governo de François Mitterand (década de 1980).

${ }^{8}$ Catálogo da I Bienal de Paris.

9 Desde 1948, quando a Bienal de Veneza voltou a ser realizada, e até 1964, a França sempre estaria presente nas premiações e conquistaria quase todos os grandes prêmios, com exceção de 1954 e 1956: Georges Braque (1948); Henri Matisse (1950); Raul Dufy (1952); Max Ernst (1954); Jacques Villon (1956); Mark Tobey (1958); Jean Fautrier, Hans Hartung e Emilio Vedova (1960); Alfred Manessier (1962). Em 1964 a hegemonia francesa é novamente quebrada, com a premiação de Robert Rauschenberg. 
representado na França pelos Salões (Salão de Maio, Salão da Jovem Pintura, Comparaisons, etc) (Lavaur, 1994: 14). ${ }^{10}$

Em livro dedicado às vanguardas no século XX e publicado em 1969, o crítico francês Pierre Restany escreve verbete sobre as Bienais de arte e tece alguns poucos comentários sobre a Bienal de Paris, centrando sua análise nas razões do sucesso da "fórmula veneziana", que vinha sendo replicada, com variantes, em diversas partes do mundo no pós-guerra (São Paulo, Tóquio, Liubliana, Menton, Teerã e San Marino são as cidades-sede de Bienais mencionadas pelo autor em seu texto). Restany atribui o sucesso veneziano a fatores como: caráter solene do evento, sistema de premiações, periodicidade, ampla confrontação de obras, criação de um público especializado. A seu ver, Veneza continuava imbatível, não tanto pela qualidade ou ousadia do evento, mas pelo enquadramento proporcionado pela cidade, pelo "ambiente, clima e pela magistral indiferença que dali emerge". Em sua opinião, as outras bienais, mais recentes, careciam do charme e da pompa de Veneza. Em relação à Bienal de Jovens de Paris, Restany ressalta seu caráter experimental, mas acredita que ela foi um passo bastante modesto na luta pela reconquista um lugar de destaque para a capital francesa no circuito mundial das artes:

Paris, certamente, ainda continua sentimentalmente ligada a seus Salões, mas acredita tão pouco em sua eficácia que não pôde resistir à tentação de criar sua própria Bienal. Raymond Cogniat, que durante muito tempo foi nosso comissário em Veneza, tinha uma posição a restabelecer e cortesias a fazer: ele encontrou uma solução elegante, criando uma Bienal de jovens artistas. Essa manifestação experimental, que se distinguia das outras cópias de Veneza, teve sucesso imediato, que se confirmou em seguida, demonstrando a eficácia da fórmula(Restany, 1969: 112-113). ${ }^{11}$

Deve-se ressaltar, contudo, que a Bienal de Paris apoiava-se fortemente no modelo das Bienais de Veneza e de São Paulo, calcado na apresentação de representações nacionais, de responsabilidade de cada país, e na atribuição de numerosos prêmios. Ao contrário de outras manifestações artísticas internacionais, de caráter periódico, que seriam criadas na segunda metade do século XX e teriam forte viés geopolítico, insistindo "em um regionalismo crítico e auto-consciente como estratégia de realinhamento de redes culturais", 12 a Bienal de Paris não contestava a "fórmula veneziana" nem sua

\footnotetext{
${ }^{10}$ Além de crítico de arte e autor de diversos livros sobre impressionismo e arte moderna, Cogniat dirigiu a revista Arts e desempenhou a função de "Inspecteur de beaux-arts".

${ }^{11} \mathrm{~A}$ seu ver, "Paris parece cada vez mais provinciana. Suas grandes discussões estéticas submergem em questões paroquiais. Ela desaprende, pouco a pouco, a ver grande. Porque Paris está realmente se tornando uma província isolada em um contexto internacional em radical evolução, apesar da presença de uma vanguarda ativa e de gritos de alarme de alguns observadores lúcidos"( Restany, 1969: 118).

12 Vide, a esse respeito, 0 artigo de Anthony Gardner e Charles Green. "Biennials of the South on the Edges of the Global". In: ThirdText, vol. 27, $n^{0}$ 4, 2013, pp. 442-455. Em seu texto, os autores se referem a eventos como a Bienal do Mediterrâneo, em Alexandria (1955), a já mencionada Bienal de artes gráficas, de Liubliana (1955) ou ainda a Bienal de Medellín, na Colômbia (1968). 
estrutura organizacional ou midiática; assim como a Bienal de São Paulo, servia-se dessa fórmula para disputar um lugar hegemônico no panorama das artes. Todavia, a seleção dos artistas franceses (ou residentes na França por ao menos três anos) se fazia de modo diferenciado (até 1965), a partir das escolhas de três comissões diferentes, formadas por jovens críticos, jovens artistas (que não participavam do evento) e pelo conselho de administração. Mas a grande novidade, como mencionado, era 0 recorte etário: para participar dessa bienal o artista deveria ter entre 20 e 35 anos. Como apontou Catherine Millet, essa opção não deixava de ser paradoxal: a bienal era uma instituição (com conselho de administração, curadores, etc), mas uma instituição que se voltava ao aleatório, ao desconhecido e não aos valores já consagrados (Millet, 1997). ${ }^{13}$

Se a princípio cada delegação podia enviar trabalhos de até 15 artistas, logo se fez necessário estabelecer um limite mais restrito de participantes por país. Em 1969, a reforma do Museu de Arte Moderna da Cidade de Paris, local que acolhia a Bienal, tornou essa questão incontornável. Para essa edição (que discutiremos adiante), as representações nacionais ficaram reduzidas a três participantes (artes visuais). Como vimos acima, na Bienal anterior, de 1967, somente a delegação brasileira levara 55 obras, de nove artistas, excluindo-se desse cômputo os trabalhos das áreas afins. Segundo dados constantes em um dos catálogos do evento, entre 1959 e 1967 cerca de 3.000 artistas, franceses e estrangeiros, haviam participado do evento, que tinha uma média de participação de 50 países. ${ }^{14}$ Lembremos ainda que os protestos de 1968, que se iniciaram na França mas se espalharam pela Europa, provocaram diversas reflexões sobre o poder e o sentido político das instituições em geral, incluindo-se aí as manifestações artísticas. A Bienal de Veneza de 1968, por exemplo, foi afetada por uma série de protestos estudantis na Itália, que resvalaram para contestações à mostra. ${ }^{15} \mathrm{Em} 1973$, sob o comando de Georges Boudaille, e sob o impacto da Documenta 5, realizada no ano anterior, a Bienal de Paris toma nova forma, dispensando as representações nacionais mas mantendo o limite de idade de 35 anos para os participantes. ${ }^{16}$ Para essa bienal e para as duas edições seguintes, a

\footnotetext{
${ }^{13}$ Enquanto os críticos franceses ressaltavam a importância do recorte etário, outros, como o português José-Augusto França, consideravam-no equivocado, sobretudo se mesclado ao "esquema veneziano". Ao escrever sobre a III Bienal de Jovens, França assinala: "O limite dos 35 anos é naturalmente ilusório e só idealmente significativo. (...) A fórmula parisiense poderia porém ter um valor operatório, se não fosse resolvida de acordo com o esquema veneziano das representações nacionais - sendo ainda mais difícil a escolha ao nível de cada país que se sente não só na obrigação de ter artistas modernos, como de os ter com menos de 35 anos. 0 que é coincidência demasiada, a todo o passo negada pela realidade" (França, 1963).

${ }^{14}$ Em 1959, 41 países participaram da Bienal de Paris; em 1965 esse número chegou a 54 (Boudaille, 1977).

15 A premiação desse ano é adiada, sendo em seguida abolida para as edições posteriores. Em 1986, porém, novo sistema de premiação é elaborado e colocado em funcionamento. Nos dizeres de Lawrence Alloway, embora a manifestação contra a Bienal se resumisse a um grupo pequeno de estudantes, e não tivesse fins precisos, o receio de que obras estrangeiras, caras, fossem vandalizadas, levou ao adiamento da premiação. "Obviamente e talvez irresistivelmente, as obras premiadas tornar-se-iam um foco para mais protestos, já que seguramente teriam uma grande cobertura pelos meios de comunicação"(Alloway, 1968: 28).

${ }^{16}$ Em texto de apresentação do catálogo da 8a. Bienal de Paris, Boudaille refere-se explicitamente a visitas que fizera à Bienal de Veneza de 1972 e à Documenta de Kassel do mesmo ano. Sobre a primeira, Boudaille afirma que a Bienal sobrevive na base de compromissos; sobre a segunda manifestação, ele comenta que o impacto positivo foi geral (Boudaille, 1973).
} 
escolha dos artistas ficou a cargo de uma Comissão internacional, composta por curadores e críticos de diferentes países, e deu-se continuidade a uma divisão dos trabalhos por temas específicos (iniciada na edição de 1971), com a seleção dos artistas sendo realizada primeiramente por correspondentes internacionais e, em seguida, por meio da análise de dossiês. ${ }^{17}$ Buscava-se, com isso, criar uma manifestação mais coerente, melhor estruturada, "passar de uma concepção muito aberta em relação a todas as formas de arte para uma mais seletiva em suas escolhas" (Lavaur, 1994: 14).

Como estratégia de afirmação, já na sua primeira edição (1959) a Bienal de Paris outorgou um número significativo de prêmios, para as duas categorias de participantes: artistas franceses e/ou residentes na França e artistas estrangeiros. Para os primeiros, a Bienal ofereceu seis bolsas, assim divididas: duas para pintura, duas para escultura, uma para gravura e uma para desenho; para os segundos, havia a oferta de 10 bolsas de residência de até seis meses na França (seis para pintura, duas para escultura, uma para gravura e uma para desenho). Além disso, mesmo que contemplado com uma das bolsas acima, o artista poderia obter outros prêmios no mesmo ano, concedidos por instituições diversas como, por exemplo, o Museu Rodin e as Edições Braun. Em 1959, o italiano GioPomodoro ganhou uma das bolsas de escultura e também o prêmio André Susse.

Interessa-me discutir aqui a participação (e premiação) dos artistas brasileiros nas Bienais de Paris dos anos 1960 e creio ser importante fazê-lo ressaltando algumas questões. A primeira diz respeito à constante $\mathrm{e}$ significativa participação do Brasil nas Bienais de Paris e, de modo geral, em eventos artísticos internacionais de grande magnitude, inclusive durante a primeira fase da ditadura militar (até a decretação do Al-5, em dezembro de 1968). ${ }^{18}$ A delegação brasileira da Bienal de Veneza de 1966, por exemplo, foi organizada por Clarival do Prado Valadares e contou com a participação de Wesley Duke Lee, Arthur Luis Piza, Sérgio Camargo (laureado na Bienal de Paris de 1963), e dos pintores naifs Francisco da Silva, José Antonio da Silva e Agostinho de Freitas. Em 1968, Jayme Maurício levou à Veneza 82 obras de Lygia Clark, em uma retrospectiva de dez anos de sua carreira, ${ }^{19}$

\footnotetext{
${ }^{17}$ Entre seus vários atos, a comissão de 1973 decide não convidar jovens artistas cujo trabalho já havia alcançado repercussão internacional, caso, por exemplo de Gilbert and George. Esse sistema funcionou até 1977. Na Bienal seguinte, que ocorreu apenas em 1980, as comissões nacionais foram retomadas.

${ }^{18}$ Como comenta Roberto Schwarz em texto escrito na época (1970) e dedicado à relação entre cultura e política, entre 1964 e 1968, embora vivêssemos sob um regime ditatorial, ainda havia espaço para contestação política, em especial no campo das artes. Schwarz afirma que "apesar da ditadura da direita [havia] relativa hegemonia cultural da esquerda no país" e que sua produção "era de qualidade notável nalguns campos". (Schwarz,1978: 62). A decretação do Al-5, em 1968 provocará uma verdadeira fratura no cenário artístico e intelectual nacional, levando diversos opositores do regime à prisão ou ao exílio.

${ }^{19}$ Além de Superfícies moduladas, dois Ovos, um Contra-relevo, quase 30 Bichos ealguns Trepantes, a mostra sobre Clark continha ainda objetos relacionais, roupas-corpo ( 0 eu e o tu e Cesariana), e ambientes, como A casa é o corpo.Ressalte-se que o Brasil contou com a publicação de um refinado catálogo à parte, financiado pelo Ministério das Relações Exteriores, com texto de apresentação e justificativa da seleção das obras, de autoria de Jayme Maurício, em italiano, inglês e português; textos de

Revista do Programa de Pós-graduação em Arte da UnB Vol.15, n²/julho-dezembro de 2016 Brasília ISSN (versão eletrônica):2447-2484
} 
além de 10 polivolumes de Mary Vieira e uma dezena de trabalhos de Farnese de Andrade, de Mira Schendel e de Anna Letycia Quadros (igualmente laureada na Bienal de Paris de 1963). Já em 1970(pós Al-5, portanto), a delegação brasileira foi bem mais modesta, composta por 16 trabalhos de Roberto Burle Marx, entre pinturas e projetos paisagísticos, e 15 obras de Mary Vieira. ${ }^{20}$

Uma situação sempre evocada em estudos sobre as artes no Brasil durante 0 regime militar foi o cancelamento da mostra dos artistas que representariam o país na VI Bienal de Jovens de Paris, em 1969. Segundo noticiou o Correio da Manhã, em 31 de maio de 1969:

aexposição dos trabalhos dos representantes brasileiros à Bienal de Paris foi desmontada horas antes da sua inauguração oficial, prevista para as 18 horas de ontem, no Museu de Arte Moderna do Rio de Janeiro, por ordem do Departamento Cultural do Ministério das Relações Exteriores. (...) 0 Departamento Cultural não tomou nenhuma outra providência no sentido de explicar como ficará a questão da representação brasileira na Bienal que será aberta, em setembro, com a participação de artistas do mundo inteiro. Os nomes dos representantes brasileiros deveriam ser comunicados àBienal, em Paris, até domingo. As obras selecionadas deveriam ser enviadas a Paris ate $1^{\circ}$ de julho..$^{21}$

A seleção, naquele ano, ficara a cargo do Museu de Arte Moderna do Rio de Janeiro, na figura de seu diretor, Maurício Roberto. Entre os nomes selecionados para integrar a delegação brasileira da Bienal de Paris estavam os de Antônio Manuel, Humberto Espíndola, Carlos Vergara e Evandro Teixeira. Algumas das obras, como Repressão outra vez: eis o saldo, de Antônio Manuel, tratavam de temas da atualidade e tinham claro conteúdo político. Esse ato repressivo, que ocorrera em seguida à apreensão de algumas obras da II Bienal da Bahia e do $3^{\circ}$ Salão de Ouro Preto, provocou reações do meio artístico brasileiro e deu início a um movimento internacional que resultaria no boicote de vários países à $X$ Bienal de São Paulo, também de 1969. Em texto de época em que comenta o boicote e que foi publicado originalmente em revista de Nova lorque, Aracy Amaral relaciona esses episódios:

As razões para o boicote [da $X$ Bienal de São Paulo] têm sua origem em violentos atos de censura, praticados desde a II Bienal da Bahia (dezembro de 1968), contra seus organizadores, incluindo a remoção de obras de arte da mostra e de exposições em Belo Horizonte e Ouro Preto. A atitude mais

apresentação dos artistas e cronologia de exposições em italiano e português, além da relação de todos os trabalhos apresentados e fotos de alguns deles.No catálogo oficial da Bienal, o texto de apresentação de Jayme Maurício é bem mais sucinto e não há menção à participação de Mary Vieira, embora uma de suas obras esteja ali reproduzida.

20 Vieira vivia na Suiça desde 1951.

21 "Itamarati [sic] cancela mostra no Museu". Correio da Manhã Rio de Janeiro, 31 maio 1969 (apud Schroeder, 2011: 35). 
chocante foi o encerramento, pelo governo, da exposição dos artistas brasileiros selecionados para a "BiennaledesJeunes" (a ser levada em efeito em Paris), que se realizava no Museu de Arte Moderna no Rio, devido a certas obras de arte que comportavam o protesto, ou eram de natureza erótica. A Associação Brasileira de Críticos de Arte (ABCA) no Rio, presidida por Mário Pedrosa, votou um manifesto de repúdio a qualquer limitação relativa à "criação da obra de arte e o livre exercício da crítica de arte", referindo-se mais especificamente aos incidentes. (...) Nos meses que se seguiram, professores universitários foram "aposentados" pelo governo, incluindo arquitetos, críticos e artistas, o que não ajudou a diminuir a tensão da atmosfera nos campos da cultura. Mais ainda, o Ministério das Relações Exteriores vetou o nome de Jacques Lassaigne, presidente da Bienal de Paris, como delegado francês, devido ao fato de ele ter assinado uma nota de protesto contra a prisão da sra. Niomar Muniz Sodré, presidente do Museu de Arte Moderna do Rio de Janeiro. Os incidentes começaram a atravessar fronteiras (Amaral, 1983: 155-156). 22

$\mathrm{Na}$ sequência, artistas de diferentes nacionalidades assinariam o manifesto Non à La Biennale, que circulava na Europa e nos Estados Unidos,e alguns países decidiriam pelo não envio de suas delegações ao evento. Pierre Restany, que foi um dos líderes do boicote, desistiu de organizar a sala especial sobre Arte e Tecnologia, que preparava juntamente com Pol Bury. Todavia, embora amplo e com adesões significativas, o boicote não foi completo e a X Bienal de São Paulo ocorreu na data prevista, com várias ausências e convidados de última hora.

Do mesmo modo, o Brasil participou da Bienal de Paris de 1969, mas apenas com duas maquetes de arquitetos paranaeneses (Abrão Assad, Roberto Gandolfi, Jaime Lerner, Luiz Forte Netto e José Sanchotene) e três composições musicais (de Almeida Prado, Cardoso Lidembergue e Marlos Nobre). No artigo já mencionado, Amaral critica "a presença de compositores brasileiros na seção de música da "BiennaledesJeunes", a despeito dos graves acontecimentos ocorridos com seus colegas do campo das artes plásticas, no Rio" (Amaral, 1983: 157). Na Bienal seguinte, em 1971, a delegação brasileira foi composta por quatro artistas plásticos - Carlos Moraes, Claudio Paiva, José Tarcísio e Wanda Pimentel -, cuja apresentação, no catálogo, fica a cargo de Walmir Ayala. Como comissário geral, o Brasil volta a designar o nome de um funcionário de Embaixada do Brasil na França, no caso Rubens Ricúpero. Isso também ocorrera nas três primeiras edições da Bienal de Paris. Em 1965, a delegação brasileira foi selecionada pelo historiador e crítico de arte baiano Clarival do Prado Valadares (que também atuou como comissário da Bienal de Veneza de 1966) e em 1967, como vimos acima, Antonio Bento foi o responsável por nossa representação.

${ }^{22} \mathrm{O}$ artigo foi publicado originalmente in Artsmagazine, Nova lorque, março de 1970. 
A segunda questão que gostaria de abordar refere-se aos vários prêmios conquistados por brasileiros nas Bienais de Paris dos anos 1960. Em relação aos outros países da América do Sul, que participaram de modo menos sistemático - ou menos expressivo - do evento, o Brasil se destaca pelo conjunto das premiações recebidas. Lembremos que o Brasil enviava representações numerosas e, ouso dizer, de qualidade. Participaram de diferentes edições das Bienais de Paris artistas cujas obras deixaram marcas na história da arte brasileira, como Willys de Castro e Glauco Rodrigues (II Bienal), Sérvulo Esmeraldo, Thomaz lanelli e Roberto de Lamonica (III Bienal), José Roberto Aguilar e Maurício Salgueiro (IV Bienal), entre outros.

As premiações foram recorrentes. Em 1959 Marcelo Grassmann ganha 0 prêmio de desenho, enquanto ManabuMabe recebe o prêmio das Edições Braun, que consistia em uma soma em dinheiro e na reprodução, pela editora, da pintura que fora selecionada pelo júri. Em 1961 Flávio Shiró é laureado com um dos oito prêmios de pintura que foram conferidos aos estrangeiros (juntamente com José BalmesParramon, do Chile). ${ }^{23}$ Destaco que o historiador Mário Barata integrou o júri internacional dessa edição. Por ocasião da III Bienal de Paris (1963), que ficou marcada pela apresentação do GRAV (Groupe de Recherche d'ArtVisuel) na seção de trabalhos de equipe e pelas obras pop da delegação arte britânica (com Peter Blake, David Hockney, Allen Jones e Philip King, entre outros), Sérgio Camargo ganhou o prêmio de escultura, juntamente com outros quatro artistas, e Anna Letycia Quadros foi agraciada pelo júri de Jovens artistas. Em 1965, foi a vez da premiação de Antonio Dias (pintura) e de Roberto Magalhães (gravura), em júri que contou com a participação de Mário Pedrosa e do argentino Jorge Romero Brest, e em 1967 Maria Bonomi ganha o prêmio da Fundação Théodoron. Nessa edição de 1967, apesar da qualidade e atualidade das obras enviadas, o Brasil ficou de fora das recompensas de maior prestígio (pintura, escultura, gravura e desenho). 0 impedimento da participação dos artistas plásticos brasileiros na Bienal de 1969 encerra, de modo lamentável, essa sequência de premiações, que em muito auxiliou a alavancar a carreira de alguns desses artistas.

Para concluir, gostaria de assinalar que embora reconheça a importância dessas premiações para nossos jovens artistas, uma pesquisa sistemática nos documentos da Bienal de Paris conservados nos Arquivos da Crítica de Arte, em Rennes, me mostrou que a repercussão desses prêmios na imprensa francesa foi mínima. Poucos foram os comentários sobre a arte brasileira ou sobre as delegações do Brasil nos artigos dedicados às Bienais de Paris, com a exceção, tímida, de algumas notas elogiosas sobre 0 trabalho de Sérgio Camargo, cujos relevos abstratos dialogavam de modo claro com a escultura moderna, em especial com o legado de Brancusi.

${ }^{23}$ Ressalto que 0 artista argentino Juan Carlos Benitez ganhou o prêmio de desenho. 
Ainda assim, alguns dos premiados residiram durante longo tempo na Europa, mais especificamente na França, como Antonio Dias (que morou em Paris de 1965 a 1968), Sérgio Camargo (que ali residiu em dois períodos distintos: de 1948 a 1954 e de 1961 a 1973) e Flávio Shiró, que escolheu a França como lugar de residência permanente. Isso talvez aponte para outras conexões, iniciadas ou fortalecidas em eventos como as Bienais de Paris.

\section{Referências}

ALAMBERT, Francisco e CANHETE, Polyana. Bienais de São Paulo. Da era do museu à era dos curadores. São Paulo: Boitempo, 2004.

ALLOWAY, Lawrence. The Venice Biennale: 1895-1968. From salon to goldfish bowl.Greenwich/Connecticut: New York GraphicSociety, 1968.

AMARAL, Aracy. "O boicote à X Bienal: extensão e significado". In: Arte e Meio Artístico : entre a feijoada e o X-burguer. Sao Paulo: Nobel, 1983.

Textos do Trópico de Capricórnio. Vol. 3.São Paulo: Ed. 34, 2006.

BOUDAILLE, Georges. "Ce qu'ilfaut savoir". Catalogue de La 8ème Biennale de Paris, 1973.

BOUDAILLE, Georges. Biennale de Paris. Uneanthologie: 1959-1967. Paris, 1977.

BAYON, Damián (org.). América Latina en sus artes. Paris (UNESCO): Siglo Veintiuno Editores, 1974. 1977.

El artista latinoamericano y su identidad. Caracas: Monte Avila Editores,

BIENNALE DE JEUNES DE PARIS. Catálogos de exposição (1959-1973).

CABANNE, Pierre e RESTANY, Pierre. L'avant-gardeauXXème. Siècle. Paris: André Balland, 1969.

Cinquenta anos de Bienais de São Paulo. Dossiê Revista USP, no 52. São Paulo, dez-fev 2001/2002.

FILIPOVIC, Elena et al. The Biennial Reader. Bergen: Bergen Kunstall e Ostfildern: HatjeCantzVerlag, 2010.

FRANÇA, José-Augusto. "A terceira Bienal de Paris". Jornal de Letras e Artes, Lisboa, nov. 1963.

GARDNER, Anthony e GREEN, Charles. "Biennials of the South on the Edges of the Global". In: Third Text, vol. 27, n0 4, 2013, pp. 442-455.

LAVAUR, Krystel. Revue de Presse. Bienal de Paris 1959-1965. Analyses e commentaires.Mémoire de DEA d'Histoire de l'art. Université Rennes 2 - HauteBretagne, 1994.

MILLET, Catherine. Introduction. In: Biennale de Paris. Une anthologie: 1959-1967. Paris, 1977.

MORAIS, Frederico. Artes plásticas: a crise da hora atual. Rio de Janeiro: Paz e Terra, 1975.

MOULIN, Raymonde. L'Artiste, l'institution et le marché. Paris: Flammarion, 1992. 
OLIVEIRA, Rita Alves. "Bienal de São Paulo: impacto na cultura brasileira". In: São Paulo em perspectiva, 15 (3), 2001, pp. 18-28.

REIS, Paulo. Exposições de arte - vanguarda e política entre os anos 1965 e 1970. Tese (Doutorado em História) - Universidade Federal do Paraná, Curitiba, 2005.

RESTANY, Pierre. "Biennales". In: CABANNE, Pierre; RESTANY, Pierre. L'avantgarde au XXème. Siècle. Paris: André Balland, 1969.

SCHWARZ, Roberto. "Cultura e política, 1964-1969". O pai de família e outros ensaios, Rio de Janeiro, Paz e Terra, 1978.

SILVA, Ana Paula F. C. "Antonio Bento e a vanguarda artística brasileira no final da década de 1960". Arte \& Ensaio. Revista do Programa de Pós-graduação em Artes Visuais, EBA/UFRJ. Rio de Janeiro, n 16, XXX, p. 44-53.

SCHROEDER, Caroline. X Bienal de São Paulo: sob os efeitos da contestação. Dissertação (Mestrado em Artes) - Universidade de São Paulo, Curitiba, 2011.

VERGER, Annie. "L'artd'estimerl'art [Comment classer l'incomparable?]". In: Actes de la recherche en sciences sociales, vol. 66-67, março 1987, pp. 105-121.

Artigo recebido em junho de 2016. Aprovado em agosto de 2016. 